\title{
Molecular mechanisms of limb regeneration: insights from regenerating legs of the cricket Gryllus bimaculatus
}

\author{
TETSUYA BANDO', TARO MITO², YOSHIMASA HAMADA*,1, YOSHIYASU ISHIMARU², \\ SUMIHARE NOJI2 and HIDEYO OHUCHI*,1

\begin{abstract}
'Department of Cytology and Histology, Graduate School of Medicine, Dentistry and Pharmaceutical Sciences, Okayama University, Okayama, Japan and 'Division of Bioscience and Bioindustry, Graduate School of Technology, Industrial and Social Sciences, Tokushima University, Tokushima, Japan
\end{abstract}

\begin{abstract}
This review summarizes recent advances in leg regeneration research, focusing on the cricket Gryllus bimaculatus. Recent studies have revealed molecular mechanisms on blastema formation, establishment of positional information, and epigenetic regulation during leg regeneration. Especially, these studies have provided molecular bases in classical conceptual models such as the polar coordinate model, the intercalation model, the boundary model, the steepness model, etc., which were proposed to interpret regeneration processes of the cockroach legs. When a leg is amputated, a blastema is formed through the activation of the Janus-kinase (Jak)/SignalTransduction-and-Activator-of-Transcription (STAT) pathway. Subsequently, the Hedgehog/Wingless/Decapentaplegic/Epidermal-growth-factor pathways instruct distalization in the blastema, designated as the molecular boundary model. Downstream targets of this pathway are transcription factors Distal-less (DII) and dachshund (dac), functioning as key regulators of proximodistal pattern formation. DII and dac specify the distal and proximal regions in the blastema, respectively, through the regulation of tarsal patterning genes. The expression of leg patterning genes during regeneration may be epigenetically controlled by histone H3K27 methylation via Enhancer-of-zeste and Ubiquitously-transcribed-tetratricopeptide-repeat-gene-X-chromosome. For the molecular mechanism of intercalation of the missing structures between the amputated position and the most distal one, Dachsous/Fat (Ds/Ft) steepness model has been proposed, in which the Ds/Ft pathway maintains positional information and determines leg size through dac expression. This model was theoretically verified to interpret the experimental results obtained with cricket legs. Availability of whole-genome sequence information, regeneration-dependent RNA interference, and genome editing technique will have the cricket be an ideal model system to reveal gene functions in leg regeneration.
\end{abstract}

KEY WORDS: leg regeneration, distalization, intercalation, steepness model, Gryllus bimaculatus

\section{Introduction}

Many regeneration processes exist that allow an organism to regrow lost body parts. Despite having distinct morphologies of regenerative organs, different organisms may share common regeneration processes. In both insects and amphibians, for instance, leg regeneration is initiated via macrophage activation (Mescher, 2017) and blastema formation, followed by proliferation, dedifferentiation, and redifferentiation of blastemal cells to generate a functional leg (Nacu and Tanaka, 2011; Das, 2015; Tanaka, 2016; Haas and Whited, 2017). Extensive genome and transcriptome sequencing data are currently available, and gene expression can be easily manipulated by gene editing methods. Applying these technological advances, researchers can study regeneration processes systematically based on gene function,

Abbreviations used in this paper: Ds/Ft, Dachsous/Fat;Jak, Janus-kinase; STAT, signaltransduction-and-activator-of-transcription.

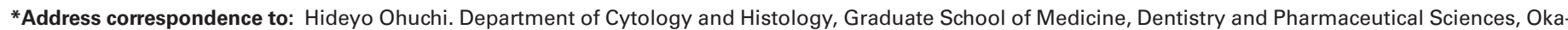

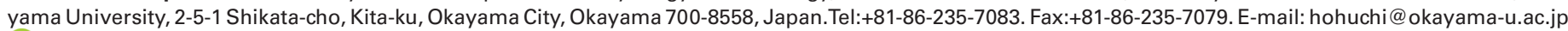
(iD) https://orcid.org/0000-0003-1961-606X - \#Present address: Division of Molecular Biology, Institute for Genome Research, Tokushima University
}

Supplementary Material (two figures) for this paper is available at: http://dx.doi.org/10.1387/ijdb.180048ho

Submitted: 31 January, 2018; Accepted: 9 February, 2018

ISSN: Online 1696-3547, Print 0214-6282 
compare regeneration processes among animals at the molecular level, and identify common basic genetic mechanisms in organ regeneration.

Historically, detailed phenomenological studies on leg regeneration of cockroach nymphs (Bohn, 1971; French et al., 1976; Truby, 1983) provided important concepts in regeneration including positional information and leading models such as the gradient (steepness) model(Bohn, 1971), the polar coordinate model (French et al., 1976), and the boundary model (Meinhardt, 1982) to explain regeneration phenomena. However, the cockroach system has become less used, probably because the fertilized eggs are surrounded by an egg case (oothecal), that makes it quite difficult to inject DNA or RNA in the egg to produce genetically-modified organisms. In contrast, in crickets, which also have remarkable regenerative capacity to restore missing distal leg parts of nymphs, eggs are easy to isolate and suitable for producing genetically-modified one to perform gene functional analyses. In addition, gene function in crickets can be studied by means of regeneration-dependent RNA interference (rdRNAi). Thus, insect leg regeneration processes have been studied at the molecular level using a cricket species Gryllus bimaculatus (two-spotted cricket; hereafter, denoted as Gb or cricket) (Mito and Noji, 2008; Wilson-Horch et al., 2017). As results, several signaling molecules and transcription factors have been identified as components of gene network pathways regulating regeneration processes in nymphal legs.

Here we review the molecular mechanisms of cricket leg regeneration, according to the distalization-and-intercalation (D\&I)

A
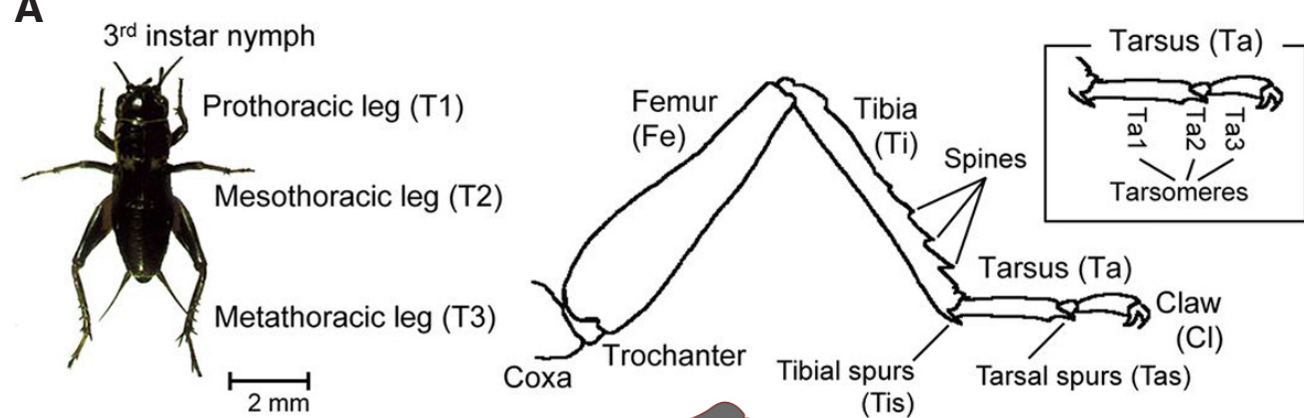

B

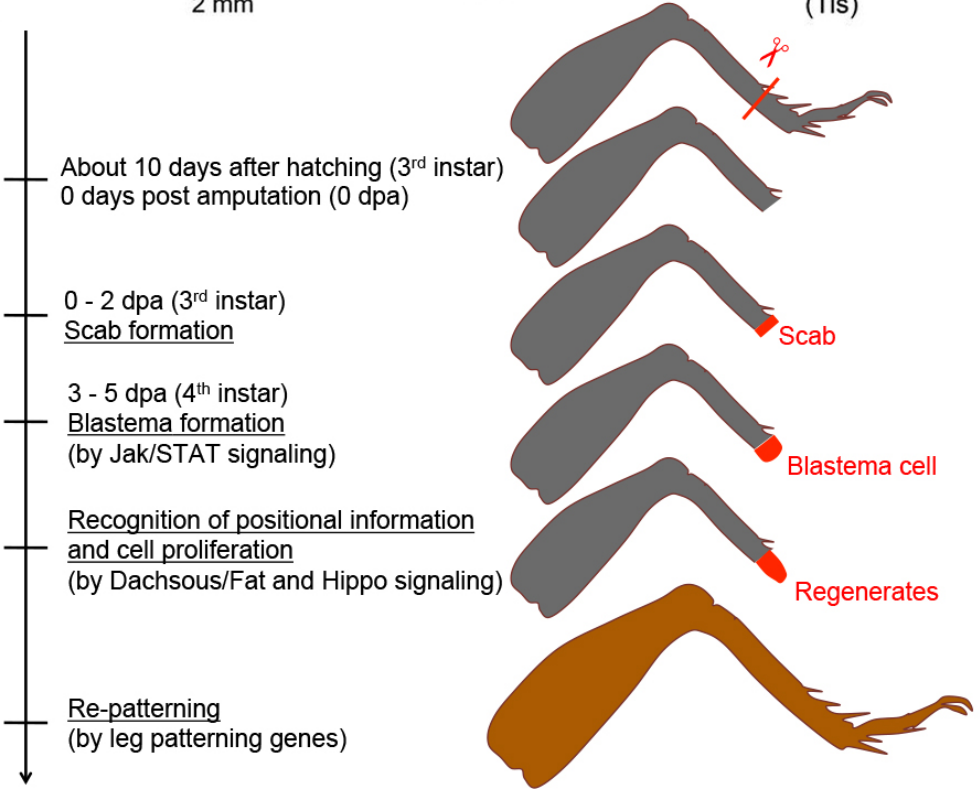

principle (Agata et al., 2007), the molecular boundary model for distalizaion, and the Dachsous/Fat (Ds/Ft) steepness model for intercalary regeneration processes. The cricket can now be used as a potent model insect to study mechanisms of leg regeneration at the gene functional level.

\section{Early processes in leg regeneration}

The cricket leg consists of six segments arranged along the proximodistal $(P / D)$ axis in the following order: coxa, trochanter, femur, tibia, tarsus, and claw (Fig. 1A). When a metathoracic leg of a cricket nymph in the third instar is amputated at a distal position of the tibia, the distal missing part is restored after four molts during the first month after amputation (Fig. 1B). After leg amputation, a blastema forms beneath the wound epidermis in a manner akin to that of other regenerative organisms. The lost part of the leg is regenerated from blastemal cells, regulated by the expression of evolutionally conserved signaling molecules. The regeneration process of cricket legs is divided into four steps: (1) wound healing with clot/scab formation, (2) blastema formation, (3) recognition of positional information and cell proliferation, and (4) repatterning (Fig. 1B).

\section{Wound healing and blastema formation in regenerative animals}

Wound healing is a conserved process observed in both regenerative and nonregenerative animals, including human. In general, wound healing involves closure of the wound surface by a clot/scab and closure of the wound surface beneath the scab by the wound epidermis. In a holometabolous insect, such as the fruitfly Drosophila melanogaster, the molecular basis of wound healing and tissue regeneration has been investigated on epidermis (Tsarouhas et al., 2014), imaginal discs (Repiso et al., 2011), and midgut (Hong et al., 2016). In the wound-healing step, the macrophage-activating pathway is likely to initiate regeneration (Mescher, 2017). In vertebrates, myristoylated alanine-rich C-kinase substrate (MARCKS)-like protein was identified as an extracellularly released factor that induces the initial cell cycle response during axolotl appendage regeneration (Sugiura et al., 2016). It is intriguing to know whether molecular and cellular bases of wound healing in crickets are similar to those found in Drosophila or in vertebrates.

Fig. 1. Structure of the cricket leg and four steps of cricket leg regeneration. (A) Dorsal view of a cricket nymph at the third instar (left) and schematic illustration of its metathoracic leg (right). (B) Amputated leg regenerates via four steps: (1) wound healing with clot/scab formation, (2) blastema formation, (3) recognition of positional information and cell proliferation, and (4) repatterning. 


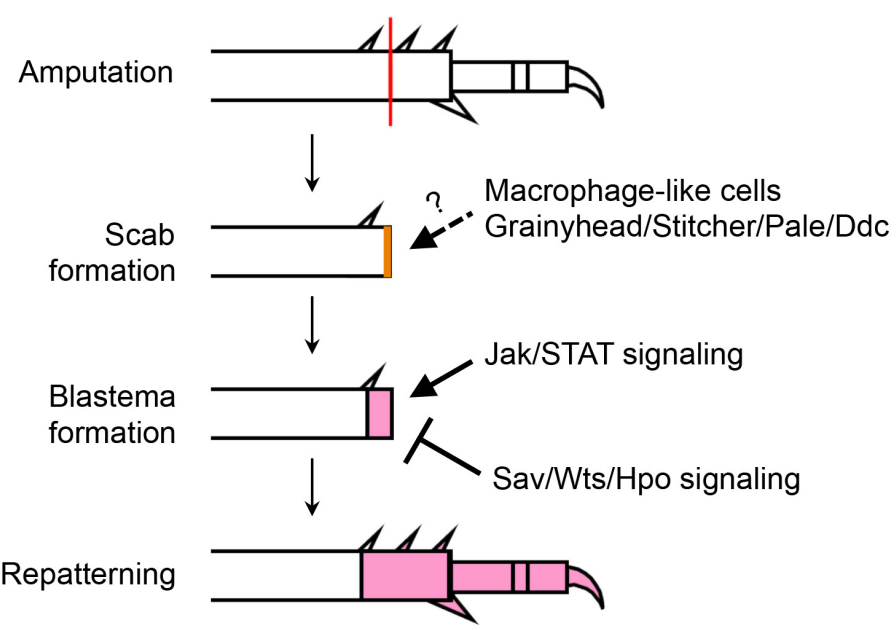

Fig. 2. Involvement of Jak/STAT and Sav/Wts/Hpo signaling pathways during cricket leg regeneration. The red line indicates the amputated position. Blastema and regenerated tissue are indicated in pink. Macrophagelike cells may be involved in scab formation, depending on gene functions of Grainyhead, Stitcher, Pale, and Dopa decarboxylase (Ddc). Jak/STAT signaling promotes blastema formation. Ds/Ft and Sav/Wts/Hpo signaling pathways inhibit proliferation of blastemal cells.

After wound healing, blastema formation is the key event for tissue regeneration. For blastemal formation, there must exist certain common basic mechanisms, because insects, small fishes, salamanders, and frogs regenerate missing tissue parts through proliferation of blastemal cells, a population of dedifferentiated proliferating cells that forms adjacently to the wound epidermis. Although cellular proliferation modes for regeneration at the stump tips differ between hydra (Galliot, 2013) and planarian (Tasaki et al., 2011a; Tasaki et al., 2011b), it seems that regeneration is commonly regulated via MAPK and Wnt signaling pathways (Petersen and Reddien, 2009; Yazawa et al., 2009). Recent advances in studies on regeneration of vertebrate appendages were reviewed in detail by Tanaka (Tanaka, 2016). Given the knowledge on early regeneration processes of invertebrates and vertebrates, secreted molecules (e.g. Unpaired (Upd) of Drosophila and MARCKS-like protein of axolotl) likely initiate blastema formation after wound closure and may regulate blastemal cell proliferation via certain signaling pathways. Roles of the signaling pathways in blastema formation will be discussed in the next section.

\section{Jak/STAT signaling is involved in cell proliferation during blastema formation in cricket}

During cricket leg regeneration, blastema forms within 2 days post amputation (dpa). Genes of several signaling molecules, including wingless/Wnt (wg/Wnt), hedgehog (hh)/Sonic hh (Shh), Epidermal growth factor (EGF), decapentaplegic (dpp)/TGF- $\beta$, Salvador (Sav)/Hippo (Hpo)/Warts (Wts), and Janus-kinase (Jak)/ Signal-Transduction-and-Activator-of-Transcription (STAT), show upregulated expression levels during blastema formation (Mito et al., 2002; Bando et al., 2009; Bando et al., 2013). Comparative RNA-sequencing (RNA-seq) data has revealed similar results in other animals (Satoh et al., 2011). Activation of Jak/STAT signaling is necessary for regeneration of the midgut and imaginal disc of Drosophila and for maintenance of the pluripotency of embryonic stem cells and induced pluripotent stem cells (Staley and Irvine,
2010). Thus, it is likely that Jak/STAT signaling plays important roles during blastema formation.

Jak/STAT signaling is evolutionarily conserved from insect to human (Arbouzova and Zeidler, 2006). Ligands for Jak/STAT signaling are secreted cytokines, including interleukins (IL-6) in vertebrates and secreted molecules (Upd, Upd2, Upd3) in Drosophila. In Drosophila, cytokines bind to an interleukin receptor Domeless (Dome) and activate a non-receptor tyrosine kinase Hopscotch (Hop), which phosphorylates the transcription factor STAT. The phosphorylated STAT homodimerizes and localizes in the nucleus to activate transcription of target genes, including cyclins and suppressor of cytokine signaling (SOCS), which negatively regulates Jak/STAT signaling by inhibiting Jak activation.

Since expression of Jak/STAT signaling genes Gb'dome and $G$ 'Stat are upregulated during cricket leg regeneration, it is suggested that this signaling is involved in the cricket blastema formation as well. RNAi-mediated knockdown of Gb'dome ${ }^{\mathrm{RNAi}}$ and $G b^{\prime} S t a{ }^{\text {NAIi }}$ show regeneration-defective phenotypes; no regeneration of lost parts of the tibia or tarsus. Gb'hop ${ }^{\mathrm{RNAi}}$ shows incomplete regeneration phenotypes; the lost part is reconstructed but with an abnormal morphology. Since expression of Gb'cyclin $E$ is decreased in the blastema of Gb'Stat ${ }^{\text {NAi }}$ crickets, Jak/STAT signaling promotes blastemal cell proliferation during leg regeneration. In

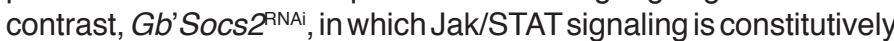
activated, shows the lengthened regenerated leg phenotype by upregulating Gb'cyclin E expression. Thus, Jak/STAT signaling is required for cell proliferation during blastema formation in the cricket leg (Fig. 2) (Bando et al., 2013).

\section{Sav/Wts/Hpo signaling suppresses blastemal cell proliferation in regenerating cricket legs}

After tissue loss, blastemal cells proliferate rapidly and differentiate into several cell types to reconstruct lost parts of the tissue. Thereafter, proliferation of differentiated blastemal cells should be suppressed. A known tumor suppressor pathway in many human cancers, Sav/Wts/Hpo is an evolutionarily conserved signaling pathway from insects to vertebrates (Harvey et al., 2013). In Drosophila, Sav/Wts/Hpo signaling regulates organogenesis, including formation of wings and compound eyes (Staley and Irvine, 2012). Key components of Sav/Wts/Hpo signaling (vertebrate homologues) are Hpo (Mst1/2), Sav (Sav1), Wts (Lats1/2), and Mats (Mob1/2). Hpo and Wts are serine/threonine kinases, while Sav and Mats are adaptor proteins for Hpo and Wts, respectively. Hpo phosphorylates and activates Wts, which phosphorylates its target protein Yorkie (Yki) to promote proteasomal degradation of Yki. Yki, a transcriptional co-activator of transcription factor Scalloped (Sd), induces expression of cyclin B, cyclin E, inhibitor of apoptosis proteins $(I A P)$, and others. The vertebrate homologue of Yki is Yap, a transcriptional co-activator that promotes cell proliferation. The vertebrate homologue of Sd is Tead, which is an antiapoptotic transcription factor. Thus, activation (or inactivation) of Sav/Wts/ Hpo signaling suppresses (or promotes) cell proliferation via inhibition (or activation) of Yki activity. Sav/Wts/Hpo signaling activity is regulated by two huge protocadherins, $\mathrm{Ds}$ and $\mathrm{Ft}$, in Drosophila. Interaction of $\mathrm{Ft}$ with Ds activates Hpo signaling to suppress cell proliferation (Cho et al., 2006).

In the early phase of cricket leg regeneration, some Hpo signaling components are upregulated. Sav/Wts/Hpo signaling may be involved in blastemal cell proliferation. RNAi-based knockdown of 
Sav/Wts/Hpo signaling component genes leads to enlargement of the blastemal region and hyperproliferation of blastemal cells in regenerating legs of $G b^{\prime} f t^{\mathrm{RNAi}}, G b^{\prime} d s^{\mathrm{RNAi}}$, and $G b^{\prime} w t s^{\mathrm{RNAi}}$ crickets. In $G b^{\prime} y k^{\text {RNAi }}$ crickets, hyperproliferation of the enlarged blastemal cells is suppressed, presumably through Sav/Wts/Hpo signaling that is activated by Ds/Ft and through Yki (Bando et al., 2009;Bando et al., 2011b). Taken together, these findings indicate that Jak/ STAT signaling promotes and Sav/Wts/Hpo signaling suppresses blastemal cell proliferation (Fig. 2). As almost all components of Jak/STAT and Sav/Wts/Hpo signaling are evolutionarily conserved from insects to vertebrates, these two signaling pathways may be involved in regulation of liver regeneration in vertebrates as well (Cressman et al., 1996; Li et al., 2002; Wuestefeld et al., 2003). Roles of Sav/Wts/Hpo signaling pathway in size control of organ regeneration were discussed by Hayashi et al., (Hayashi et al., 2015b) and also in this Review.

\section{Molecular systems to establish positional information during leg regeneration}

\section{The distalization-and-intercalation principle}

In the 1900s, Thomas Hunt Morgan categorized tissue regeneration in animals into two modes: morphallaxis and epimorphosis (Morgan, 1901). In the case of cricket leg regeneration, the residual part of the leg appears to remain as it is and the lost parts are added on. This kind of regeneration is called "epimorphic regeneration".
A

$$
\begin{aligned}
& \text { Drosophila } \\
& \text { Leg development }
\end{aligned}
$$
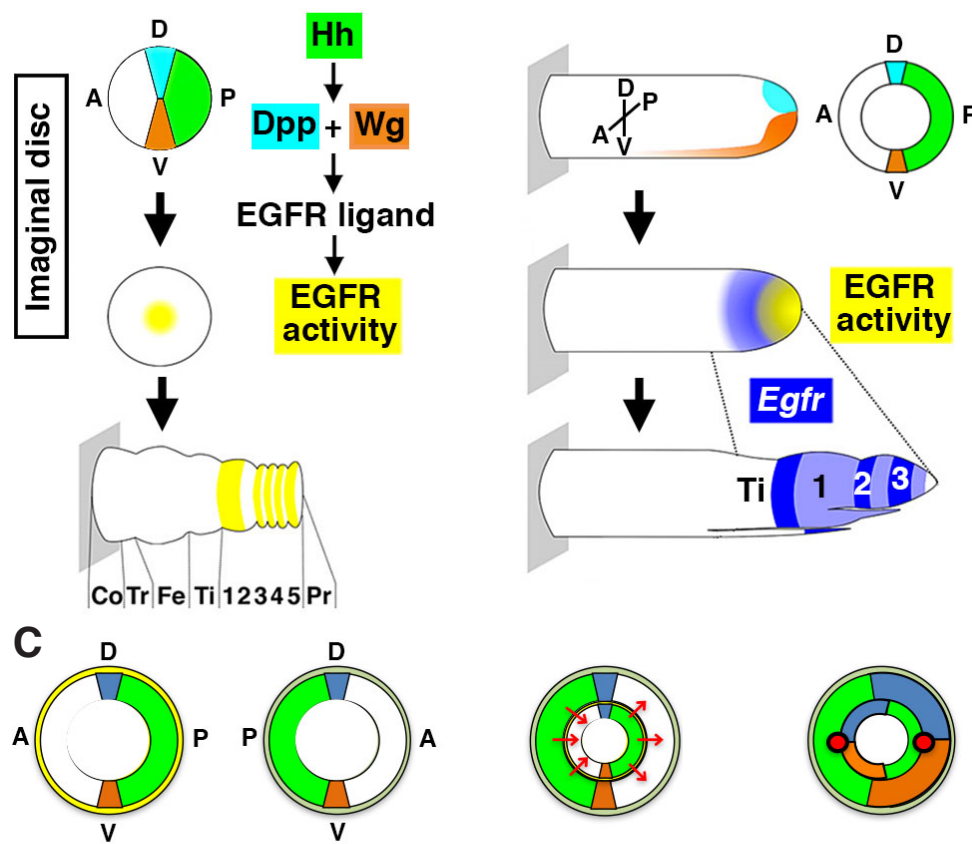

B

\section{Leg regeneration}

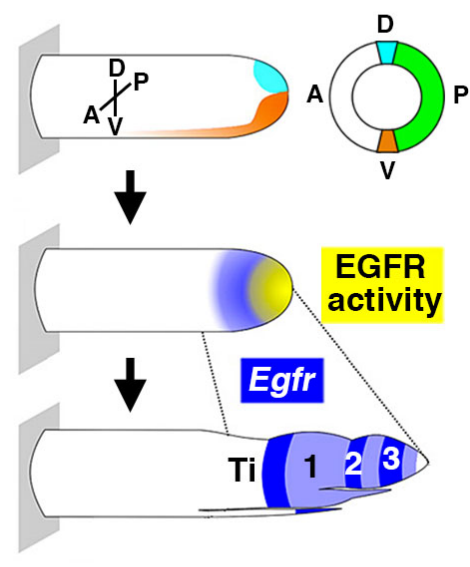

On the other hand, lost body parts of hydra are reconstructed morphallactically: when the head or tail region of hydra is lost, whole body parts are completely reconstructed in the remaining parts in miniature. The reconstructed miniature part then grows to recover the original size and shape without blastema formation in the hydra. In 2007, Agata et al., (Agata et al., 2007) observed that regeneration of the planarian is neither morphallactic nor epimorphic. They proposed a new unifying principle, called "distalization and intercalation" (D\&I) principle. It is likely that when animals lose body parts, such as limbs (for newts and salamanders), tails (for tadpoles), caudal fins (for zebrafish), or legs (for insects and other cases), animals should recognize the amputated position as the most distal position. Then, they reconstruct the lost parts similarly to the original ones from blastema by intercalating parts between the most distal position and the remained position with changing the remaining part of the tissue. So far, the molecular boundary model has been proposed for initiation of pattern formation (i.e., "distalization"), while the Ds/Ft steepness model has been applied for intercalary pattern formation during regeneration (i.e., "intercalation").

\section{The molecular boundary model for distalization}

In newts and cockroaches as well as crickets, supernumerary legs are formed at anterior and posterior sides of the grafting position, when the distal graft piece is transplanted to the contralateral host stump. French and colleagues proposed the polar coordinate model to interpret this phenomenon (French et al., 1976; Bryant et al., 1981). The model includes two rules: the shortest intercalation rule and the full circle rule. The shortest intercalation rule states that discontinuity of positional information between the host stump and graft piece is recovered

Fig. 3. Schematic model of distalization and its molecular players. (A) In the early Drosophila leg imaginal disc, hh (green) is expressed in the posterior compartment, while dpp (light blue) is expressed dorsally and wg (orange) ventrally at the anteroposterior boundary. High activity levels of Dpp and Wg induce expression of an EGFR ligand at the center of the leg disc. A distal-to-proximal gradient of EGFR activity is found in the presumptive distal segments (yellow), in which EGFR signaling activation appears inside each leg segment (yellow). (B) Regeneration of cricket leg amputated at distal tibia. During early regeneration, $\mathrm{Gb}$ 'hh (green) is expressed in the posterior blastemal cells, and Gb'dpp (light blue) and Gb'wg (orange) are expressed in dorsal and ventral blastema, respectively. Gb 'Egfr (blue) is broadly expressed in distal blastema. EGFR activity is shown in yellow. In later regenerating legs, Gb'Egfr expression forms rings adjacent to presumptive joints between regenerating leg segments. Panels A and B are modified from Fig. 7 in Nakamura et al., (2008b). (C) A mode of formation of supernumerary legs by grafting operation in the cricket nymph based on the CTBM. When the right mesothoracic leg (T2) of the graft (ventral view) grafted into the left metathoracic leg (T3) of the host (ventral view) to reverse the anteroposterior polarity, Gb'Hh (green) in the posterior compartment of the host and graft legs induces the expressions of Gb'dpp (light blue) and Gb'wg (orange) in the dorsal side and ventral side of the anterior compartment (red arrows). The site where the Gb'dpp-expression cells abuts the Gb'wg-expressing cells becomes an organizer that induces the formation of the P/D axis (red circles). Co, coxa; Tr, trochanter; Fe, femur; Ti, tibia; $T a$, tarsus; 1, 2, 3, 4, 5, tarsal segments 1-5; Pr, pretarsus; $A$, anterior; $D$, dorsal; $P$, posterior; $V$, ventral. 
by intercalating the minimum missing positional information to continue the discontinuity, although the direction of the intercalate is forwarded or reversed. The full circle rule states that leg outgrowth will occur where there is a complement of circumferential positional information. According to the polar coordinate model, supernumerary leg outgrowth occurs when there is discontinuity of circumferential positional information and intercalates the gap of positional information (French et al., 1976).

The boundary model was proposed to explain that these phenomena would be promoted by local interaction of tissue compartments (Meinhardt, 1983). Afterward, the molecular basis of the boundary model was clarified through intimate gene expression analysis of Drosophila leg imaginal disc (Campbell and Tomlinson, 1995). In their model (Campbell and Tomlinson boundary model: CTBM), the posterior compartment of leg imaginal disc is defined by the expression of engrailed, which encodes a homeoprotein. $d p p$ is expressed by the dorsal cells at the anteroposterior (A/P) boundary, whereas $w g$ is expressed by the ventral boundary cells (Fig. $3 \mathrm{~A})$. The crossing point of the $d p p$-expressing cells and the $w g$ expressing cells is the presumptive distal tip, which is a molecular base for "distalization" during limb development. It should be noted that while the number of circumferential positional values are drawn to be 12 as a familiar clock face in the polar coordinate model, three compartments, posterior, antero-ventral, and antero-dorsal, are enough for distalization in insect limb development (Vincent and Lawrence, 1994).

The CTBM model was subsequently found to suit well to cricket leg regeneration (Mito et al., 2002). Gb'hh is expressed in the posterior compartment in the regeneration blastema, whereas $G b^{\prime} d p p$ and $G b^{\prime} w g$ are expressed in the dorsal and ventral cells at the A/P boundary, respectively (Fig. 3B). These gene expression patterns are comparable to those of the leg bud of cricket embryo and the leg imaginal disc of Drosophila (Niwa etal., 2000; Mito et al., 2002), suggesting that leg regeneration along the P/D axis goes through a distalization process similarly to normal leg development. In the case of grafting experiments involving formation of supernumerary legs, the posterior cells are forced to confront the anterior cells and two new interfaces are formed (Fig. 3C). Since Hh induces dpp or wg expression in the Drosophila leg imaginal disc (Fig. 3A) (Campbell et al., 1993; Basler and Struhl, 1994; Diaz-Benjumea et al., 1994), Gb'Hh secreted from the posterior compartment likely induces expression of Gb'dpp and Gb'wg in the dorsal and ventral boundary cells, respectively. In this way, leg regeneration along the $\mathrm{P} / \mathrm{D}$ axis is triggered at the boundary cells of $G b^{\prime} d p p$-expressing domain and Gb'wg-expressing domain, which has been verified by RNAi-based functional studies (Mito et al., 2002).

In the Drosophila leg imaginal disc, a combined activity gradient of Dpp and Wg activates downstream gene expression along the leg P/D axis. The highest $d p p$ and wg expression levels induce vein $(v n)$, which encodes a ligand of EGF receptor (EGFR) (Campbell, 2002; Galindo et al., 2002). Vn acts as a principal morphogen for distal leg patterning by activating EGFR signaling, indicating that the tarsus may be patterned by a distal-to-proximal gradient of EGFR activity (Fig. 3A) (Campbell, 2002; Galindo et al., 2002). During leg regeneration, Gb'Egfr expression is observed in the blastema, whereas its expression is maintained as ring-like adjacent to presumptive intersegmental borders in the later regenerating leg (Fig. 3B) (Nakamura et al., 2008b). Gb'Egfr was shown to be required for formation of distal leg structures, specifically the distal tarsus and claws, in the regeneration process and supernumerary leg formation (Nakamura et al., 2008a; Nakamura et al., 2008b). Thus, Gb'Egfr is essential for distalization to regenerate distal tarsal structures and claws. This finding is consistent with the role of EGFR signaling during Drosophila leg development (Campbell, 2002). These findings indicate that the molecular mechanisms for distalization shown in the CTBM model well explain the various phenomena observed during formation of the P/D axis in the developing and regenerating insect leg. Recently, Nacu et al., (Nacu et al., 2016) identified single factors that can substitute for functions of anterior and posterior tissue, Shh for posterior and Fibroblast Growth Factor 8 (FGF8) for anterior tissue, in supernumerary limb formation in axolotls. This observation suggests that in axolotls the CTBM model works under different molecular players from those of insects.

\section{Role of P/D-patterning genes (Gb'EGFR, Gb'al, Gb'DIl and Gb'dac) during establishment of segment identity in regenerating legs}

In Drosophila imaginal disc, genes involved in establishing the $P / D$ axis of the leg are induced by the EGFR signaling pathway. $D / l$ is indispensable for development of distal leg parts (Cohen et al., 1989), dac is required for development of medial leg parts (Mardon et al., 1994; Dong et al., 2001), and homothorax (hth) instructs proximal leg fates (Rieckhof et al., 1997;Wu and Cohen, 1999). In the cricket leg bud, segment identity may be determined by Gb'DII, Gb'dac, and Gb'hth genes (Inoue et al., 2002), as in the Drosophila imaginal disc (Goto and Hayashi, 1999; Kojima, 2004). In the blastema, Gb'DIl, Gb'dac, and Gb'aristaless (al) genes are expressed in a manner that is similar to that observed in developing leg buds (Nakamura et al., 2008a; Nakamura et al., 2008b). Thus, a common mechanism for P/D patterning is likely to exist between leg buds and blastema.

A model for P/D patterning of regenerating legs is shown in Fig. 4 (Ishimaru et al., 2015). Gb'DIl is expressed in the blastema that corresponds to tarsal segments $1-3$, and higher expression is
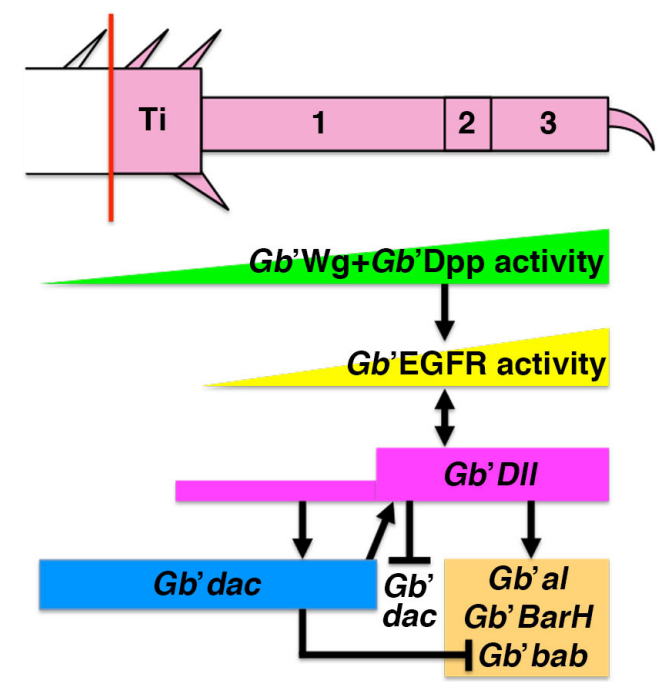

Fig. 4. Schematic model of repatterning process during cricket leg regeneration. Schematic of transcriptional regulation by tarsal repatterning genes to form tarsal segments (see the text for details). The amputated position is shown in red lines. Regenerated segments are indicated in pink Ti, tibia; 1, 2, 3, tarsal segments 1-3. 


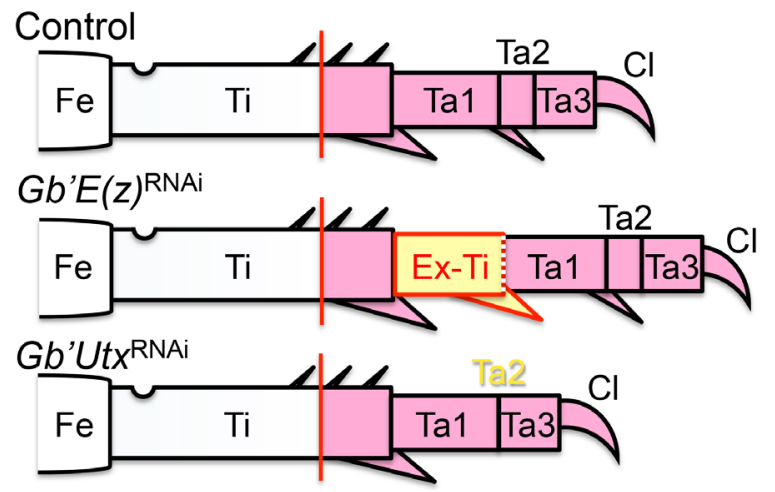

Fig. 5. Schematic diagrams of regenerated leg phenotypes in control,

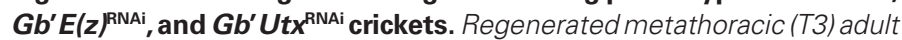
legs shown in pink. Fe, femur; Ti, tibia: Ta 1-3, tarsal segments 1-3; Cl, claw; Ex-Ti, extra-tibia (in yellow).

involved in the most distal region. When higher Gb'Dll expression is induced by Gb'EGFR signaling in the most distal region, Gb'dac expression is substantially reduced, and tarsal appendage-patterning genes, such as Gb'al, Gb'BarH, and Gb'bric a brac (Gb'bab), are expressed in the distal region. Therefore, $G b^{\prime} D / l$ is critical for tarsus regeneration, and the formation of tarsal segments 2-3 may be regulated by expression of these patterning genes. Conversely, in the proximal regions where Gb'DIl expression is low, Gb'dac expression is increased whereas $G b^{\prime} b a b$ expression is repressed, and consequently formation of tarsal segment 1 is induced. Thus, Gb'dac is essential for regeneration of tarsal segment 1. These observations lead to the conclusion that $G b^{\prime} D / l$ acts as a negative or positive regulator for $G b^{\prime} d a c$ expression, depending on its expression level, in the formation of tarsal segments along P/D axis. During establishment of the P/D axis in leg regeneration, cell proliferation appears to be promoted in the presumptive tarsus and tibia. Cell proliferation is mainly affected by Gb'dac expression, and $G b^{\prime}$ dac may contribute to elongation of the regenerating tarsal segment 1 (Ishimaru et al., 2015). Furthermore, Gb'dac affects tibial cell proliferation and is associated with the size determination of regenerating tibia along the P/D axis through $G b^{\prime} \mathrm{Ds} / G b^{\prime} \mathrm{Ft}$ signaling (Ishimaru et al., 2015).

\section{Epigenetic regulation of leg patterning genes during repatterning process}

Epigenetic control of gene expression via chemical modification of the histone tail is a conserved mechanism to regulate pattern formation in animal development. However, the way of its involvement in pattern formation may vary among species (Supplemental information and Fig. S1). Pattern formation of developing limbs in mice is regulated by $\mathrm{HOX}$ genes (a subset of homeotic genes) whose expressions are epigenetically regulated by Ring finger protein 1 (Ring1), an essential component of Polycomb repressive complex 1 (Yakushiji-Kaminatsui et al., 2016). Segment patterns in insect embryos, including Drosophila, Tribolium, and Gryllus, are regulated by $H O X$ genes whose expressions are epigenetically controlled by Polycomb group proteins (Matsuoka et al., 2015). Expressed-gene sets and gene expression patterns are similar between regenerating legs and developing legs in the cricket ( $\mathrm{Na}$ kamura et al., 2008b;Donoughe and Extavour, 2016), indicating that epigenetic regulation is involved in nymphal leg regeneration. Indeed, comparative transcriptome analysis shows that expressions of several epigenetic factor genes are upregulated in regenerating legs at 24 hpa compared to 0 hpa (Bando et al., 2013).

Epigenetic regulation via methylation of the $27^{\text {th }}$ lysine residue of histone $\mathrm{H} 3$ (H3K27) is known to transform euchromatin into heterochromatin, which in turn represses gene expression, and vice versa (Tie et al., 2009). Methylation status of histone H3K27 is regulated by a single histone methyltransferase and a single histone demethylase in insects: Gb'Enhancer of zeste $\left(G b^{\prime} E(z)\right)$

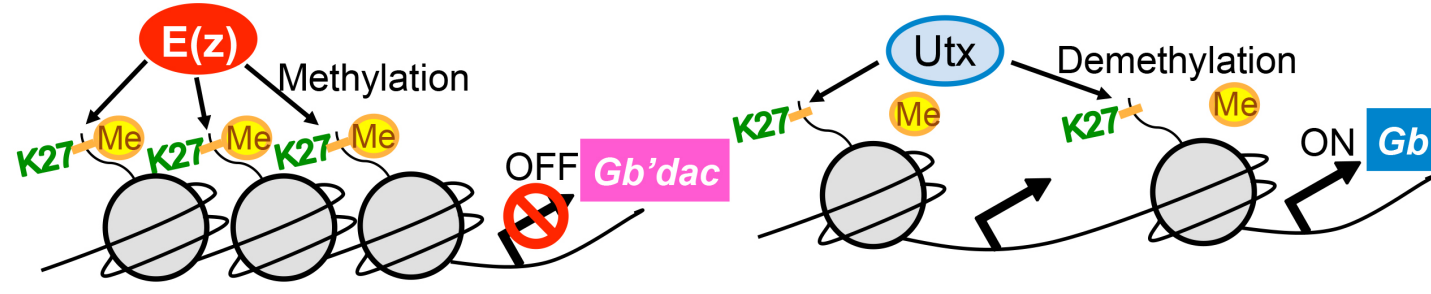

Amputation
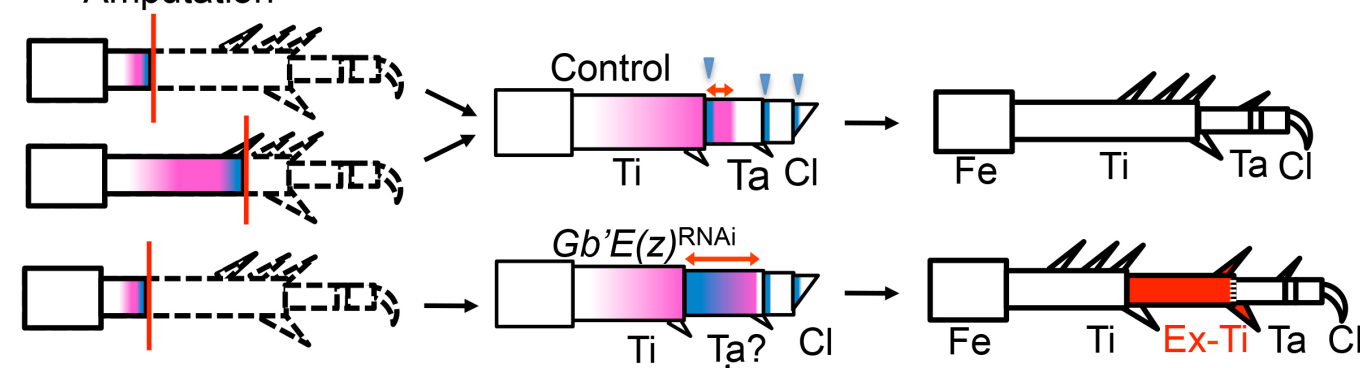

$\mathrm{Ti}^{\mathrm{Ta}} \mathrm{C}$

$\longrightarrow$ Tibialize a part of tasus
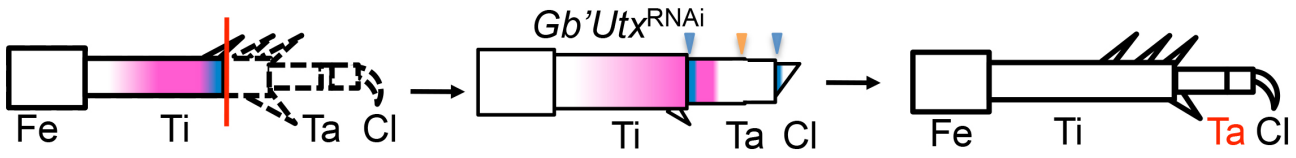

Fig. 6. Typical regenerated leg phenotypes, leg patterning gene expression, and plausible model for repatterning. Plausible models of repatterning process in control, Gb' $\mathrm{E}(\mathrm{z})^{R N A i}$ and $\mathrm{Gb}^{\prime} \mathrm{Utx}{ }^{R N A i}$ regenerating legs (see details in text). Gb'dac and Gb'Egfr are illustrated by magenta and blue, respectively. Double-headed red arrows indicate Gb'dac expressing domains in extra-tibia and tarsus regions. Blue and orange arrowheads indicate Gb'Egfr expression and diminished Gb'Egfr expression, respectively (Partly adapted from Fig. 8 of the reference (Hamada et al., 2015)). Fe, femur;Ti, tibia:Ta, tarsal segments; Cl, claw; Ex-Ti, extra-tibia (in red). 
and Gb'Ubiquitously transcribed tetratricopeptide repeat gene, $X$ chromosome ( $G b^{\prime} U t x$ ) encode a methyltransferase and demethylase of histone H3K27, respectively. Gb'E(z) and Gb'Utx expressions are upregulated and ubiquitously expressed in regenerating legs, respectively. The distribution of trimethylated histone H3K27 (H3K27me3) is reduced in $G b^{\prime} E(z)^{\mathrm{RNAi}}$ legs and increased in Gb'Utx ${ }^{\mathrm{RNAi}}$ legs. In Gb'Utx ${ }^{\mathrm{RNAi}}$ regenerated legs, tarsal segments 1 and 2 are fused, and tarsal spurs are not restored (Fig. 5). On the other hand, in $G b^{\prime} E(z)^{\mathrm{RNAi}}$ regenerated legs, an additional segment is regenerated between original tibia and tarsal segment 1 in the most severe phenotype (Fig. 5). By analyzing morphological structures and expression patterns of leg patterning genes, the additional segment by $G b^{\prime} E(z)^{\text {RNAi }}$ turns out to be a tibia, designated extra-tibia (Ex-Ti).

To elucidate the epigenetic mechanism to induce formation of the additional leg segment of Ex-Ti, expression patterns of leg repatterning genes, including Gb'dac, Gb'DII, Gb'Egfr, and Gb'BarH, were examined (Hamada et al., 2015). Correlation between the RNAi phenotypes and expression patterns of leg patterning genes is schematically shown in Fig. 6. In $G b^{\prime} E(z)^{\mathrm{RNAi}}$ regenerating legs, Gb'dac expression is expanded in tarsal segment 1 . This ectopic expression of Gb'dac may induce tibialization of a part of tarsus, resulting in additional tibial formation. In Gb'Utx ${ }^{\mathrm{RNAi}}$ regenerating legs, expression of Gb'Egfr is diminished in the middle tarsus, which may inhibit leg joint formation in the tarsus. Thus, epigenetic regulation of gene expression via histone H3K27me3 controls leg regeneration along the P/D axis. In conclusion, histone H3K27 methylation via $G b^{\prime} E(z)$ and its demethylation via $G b^{\prime} U t x$ epigenetically controls the expression of leg patterning genes (Hamada et al., 2015). Roles of epigenetic regulation via histone H3K27 methylation during regeneration has been also discussed in Drosophila imaginal disc regeneration (Repiso et al., 2011) and Xenopus limb regeneration (Hayashi et al., 2015a).

\section{The Ds/Ft steepness model for intercalation}

\section{Intercalary regeneration}

In 1971, a paper entitled "Intercalary Regeneration and Segmental Gradients in the Extremities of Leucophaea (Blattaria) Larvae" was published and a gradient (steepness) model for intercalation was proposed (Bohn, 1971). There is a grafting experiment on cricket legs, in which a short graft amputated at the distal position of the tibia is transplanted into another amputated host, which is shortened at the proximal position of tibia, with lacking the middle region of the tibia. After transplantation, crickets undergo "intercalary regeneration" of the lost middle region between the host and graft to recover the discontinuity (Fig. 7). When a long graft that was amputated at the proximal position of the tibia is transplanted into another long host, which is amputated at the distal position of the tibia, with overlapping of the middle region of the tibia from host and graft. In this case, "reversed intercalary regeneration" of the overlapping middle region is observed in the opposite direction along the P/D axis (Fig. 7). In both cases, the intercalated parts are originated from the segment that has distal identity. When discontinuity of positional information occurs by amputation or transplantation of legs, the legs intercalate lost parts to retrieve missing positional information (Bohn, 1971; French et al., 1976). On the other hand, in 1978, a paper entitled "Intercalary regeneration around the circumference of the cockroach leg" was published and

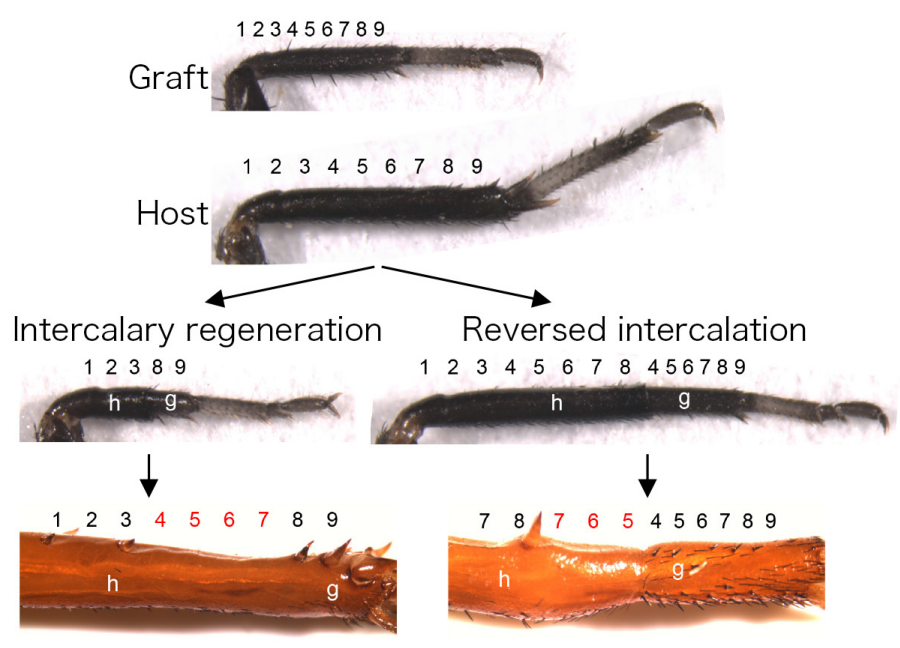

Fig. 7. Intercalary regeneration and reversed intercalation in the cricket leg. Intercalary regeneration: When distally amputated mesothoracic leg ( $g$, graft) is transplanted to proximally amputated metathoracic leg (h, host), the middle region is intercalarily regenerated (red numbers). Reversed intercalation: When proximally amputated mesothoracic leg ( $g$, graft) is transplanted to distally amputated metathoracic leg (h, host), the middle region is duplicated in the opposite direction.

it was demonstrated that cells at different positions have different positional values in a circumferential sequence, which is analogous to the proximal/distal sequence (French, 1978). It is interesting to note that when the tibia and the femur are amputated at the same position and then the tibial graft is transplanted to the host, no intercalary regeneration occurs. This indicates that positional information along the P/D and circumferential axes is equivalent in each leg segment, suggesting that the molecular basis of positional information should be reiterated in each leg segment in a gradient manner along these axes (Bando et al., 2009).

\section{Involvement of the Ds/Ft signaling pathway in maintaining positional information during intercalation}

To explain intercalary regeneration at a molecular level, Bando et al., (Bando et al., 2009; Bando et al., 2011b) proposed the Ds/ Ft steepness model. It has been known in Drosophila that Ds and Ft are expressed in imaginal discs in a counter-gradient manner and regulate morphogenesis of several organs, including eyes, wings, and legs. As huge protocadherins found at the adherence junction of the cell membrane, Ds and Ft interact with each other to regulate cell-cell contacts. Heterodimerization of Ft with Ds activates Sav/Wts/Hpo signaling to transduce cell-cell contacts and regulate cell proliferation, apoptosis, planer cell polarity (PCP), and cell morphology. Signal transduction from Ds/Ft to Sav/Wts/Hpo is mediated by an unconventional myosin Dachs (D) and a novel dsRNA binding protein Lowfat (Lft). Regulation of PCP by Ds/Ft involves a multifunctional Golgi kinase, Four-jointed (Fj) (Harvey and Hariharan, 2012; Staley and Irvine, 2012). These characteristics indicated that Ds and Ft are good candidates for molecules related to positional information.

In cricket legs, $G b^{\prime} d$ sand $G b^{\prime} f t$ are expressed in each leg segment of developing limbs and regenerating legs in a counter-gradient manner along the P/D axis. Gb'd and Gb'fj/Gb'lft are expressed 
A

Control

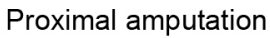

Middle amputation

Distal amputation

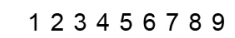

Gb'ftRAi
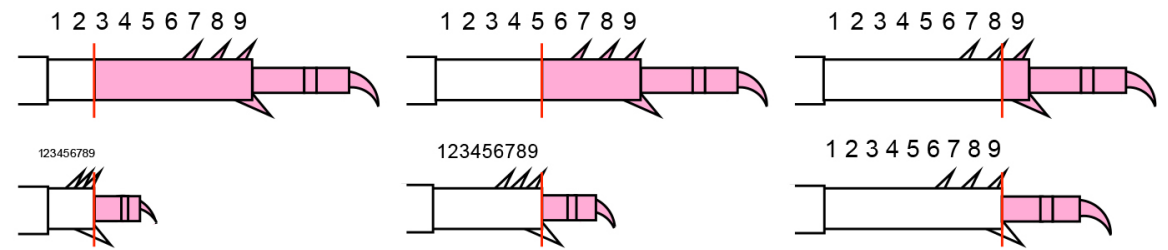

B

Intercalary regeneration

Reversed intercalation
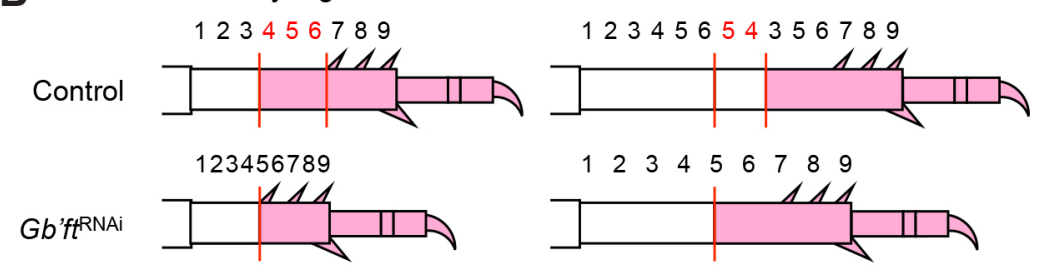

$\begin{array}{lllllllll}1 & 2 & 3 & 4 & 5 & 6 & 7 & 8 & 9\end{array}$

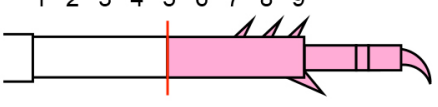

C

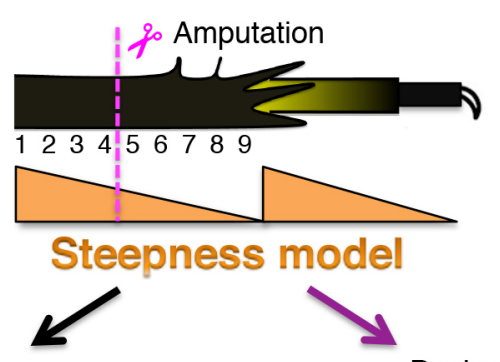

Normal

regeneration

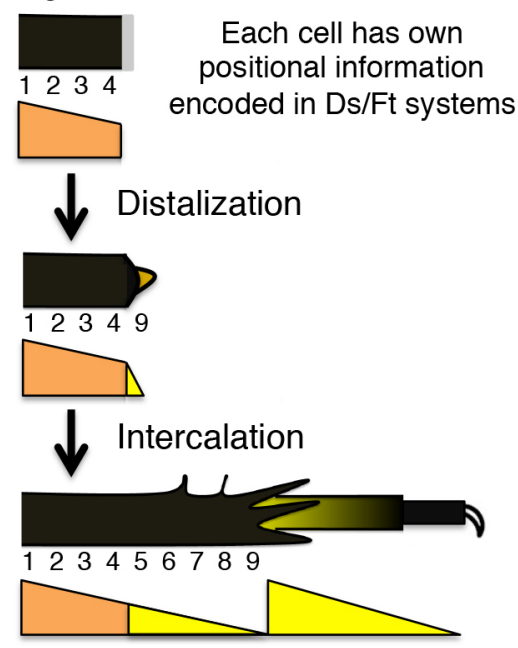

Dachsous/Fat

RNAi
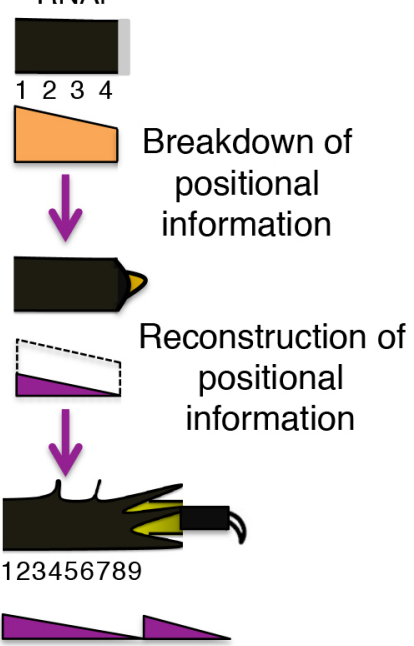

Fig. 8. Involvement of $\mathrm{Ds} / \mathrm{Ft}$ signaling in regeneration and a steepness model. Summary of leg regeneration and transplantation in control and $\mathrm{Gb}^{\prime} \mathrm{ft}^{\mathrm{RNAi}}$ crickets. Amputated positions are shown in red lines, regenerated tissues in pink, and plausible positional information in numbers. (A) In control cricket, the lost part of the leg regenerates as the original one independently of the amputated position. In Gb'ds ${ }^{\text {RNAi, }} \mathrm{Gb}$ ' $\mathrm{ft}^{\text {RNAi }}$ $\mathrm{Gb}^{\prime} \mathrm{d}^{\text {RNAi}}$, or $\mathrm{Gb}$ Ift ${ }^{\text {RNAi }}$ crickets, regenerated legs are shortened depending on the amputated positions. (B) When a graft piece is transplanted into different positions of the host, discontinuity is recovered by intercalation in the control. Intercalation does not occur in $\mathrm{Gb}^{\prime} \mathrm{ds}^{\text {RNAi, }} \mathrm{Gb}$ 'ft ${ }^{R N A i}$, or Gb'd ${ }^{R N A i}$ crickets. Positional information of intercalated regions is shown in red numbers. (C) Normal regeneration: schematic of the steepness model for leg regeneration. After amputation at positional value (PV) $=4$ in tibia (with tibial stump in orange), blastemal cells detect positional disparity (PV, 4/9). The most distal PV is established (distalization) by the mechanism proposed by the molecular boundary model. A steep slope is formed, which leads to intercalary growth until positional continuity is re-established (yellow, $P V=4 \sim 9)$, as epimorphic-like regeneration. Pre-existing stump (orange) grows allometrically, retaining the original positional and allometric information (PV = 1 4). Ds/Ft RNAi (purple arrows): In $\mathrm{Gb}^{\prime} \mathrm{ds}{ }^{\text {RNAi }}$ or $\mathrm{Gb}$ 'ft ${ }^{\text {RNAi }}$ nymphs after amputation, remodeling of the stump takes place as morphallaxis-like regeneration. The normal Ds/Ft gradient (dotted line) shifts down with the same slope (purple), thus resetting the positional value of the amputated surface to the most distal positional value or the minimum scalar value of the Ds/Ft gradient. similarly to $G b^{\prime} d s$ and $G b^{\prime} f t$, respectively, suggesting that the regulation of positional information may involve Ds/Ft signaling (Bando et al., 2011a; Bando et al., 2011b). If this possibility were true, then signaling knockdown would cause morphological defects along the P/D axis during regeneration and intercalation. As expected, regenerated legs of $G b^{\prime} d s^{\mathrm{RNAi}}$ and $G b^{\prime} f^{\mathrm{t} \text { RAA }}$ are shortened and thickened, respectively, and those of $G b^{\prime} d^{\mathrm{RNAi}}$ and $G b^{\prime} / \mathrm{ft}^{\mathrm{RNAi}}$ are shortened. Regenerated legs of $G b^{\prime} d s^{\mathrm{RNAi}}, G b^{\prime} f t^{\mathrm{RNAi}}$ (Fig. 8A), $G b^{\prime} d^{R N A i}$ and $G b^{\prime} / f^{R N A i}$ are shortened depending on the amputated position along the P/D axis, while in control amputation the length of regenerated legs is almost the same as that of the contralateral legs. Although the regenerated leg of $G b^{\prime} f^{\mathrm{RNAi}}$ is very short after the tibia is amputated at the proximal position, the tarsus, claw, and tibial and tarsal spurs are reconstructed at relative positions (Fig. $8 \mathrm{~A})$. One explanation for this phenomenon is that rearrangement of positional information in the amputated leg stump shrinks the leg structures (Fig. 8C).

If positional information is rearranged after knockdown of Ds/ Ft signaling, then intercalary regeneration would be changed. In the control cricket, when a graft piece is transplanted into the host stump at different positions to induce discontinuity of positional information, intercalary regeneration or reversed intercalation occurs to recover the continuity of positional information. In contrast, no regeneration phenomenon occurs in $G b^{\prime} d s^{\mathrm{RNAi}}, \mathrm{G} b^{\prime} f^{\mathrm{RNAi}}$ (Fig. 8B), or $\mathrm{Gb}^{\prime} \mathrm{d}^{\mathrm{RNAi}}$ crickets (Fig. 8B). Thus, it can be concluded that Ds/ Ft through $D$ maintains positional information along the P/D axis 


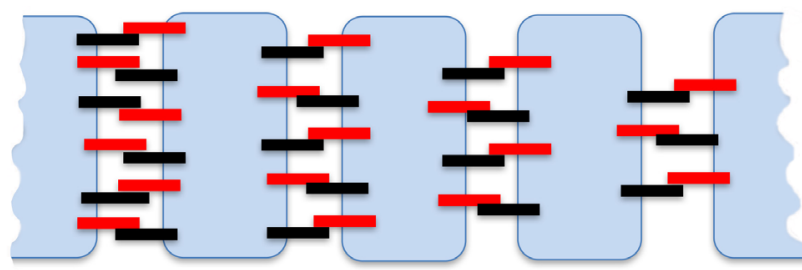

: Dachsous (Ds)/Fat(Ft) heterodimer

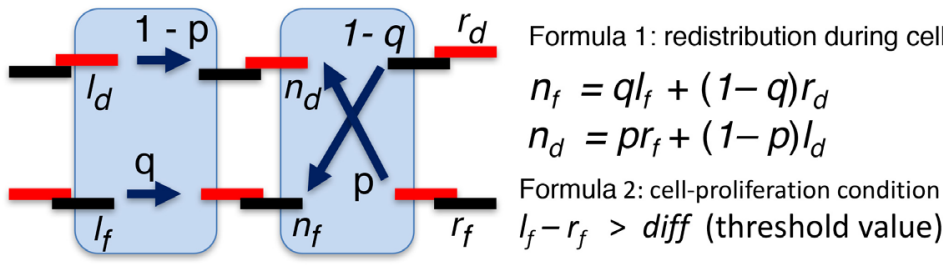

in leg segments during regeneration and intercalation. Lft helps to maintain positional information during longitudinal regeneration but is not needed during intercalation (Bando et al., 2009;Bando et al., 2011a;Bando et al., 2011b). Protocadherins Ds and Ft are evolutionarily conserved from insects to vertebrates. However, maintenance of positional information via Ds/Ft signaling during tissue regeneration has not been analyzed in other regenerative animals.

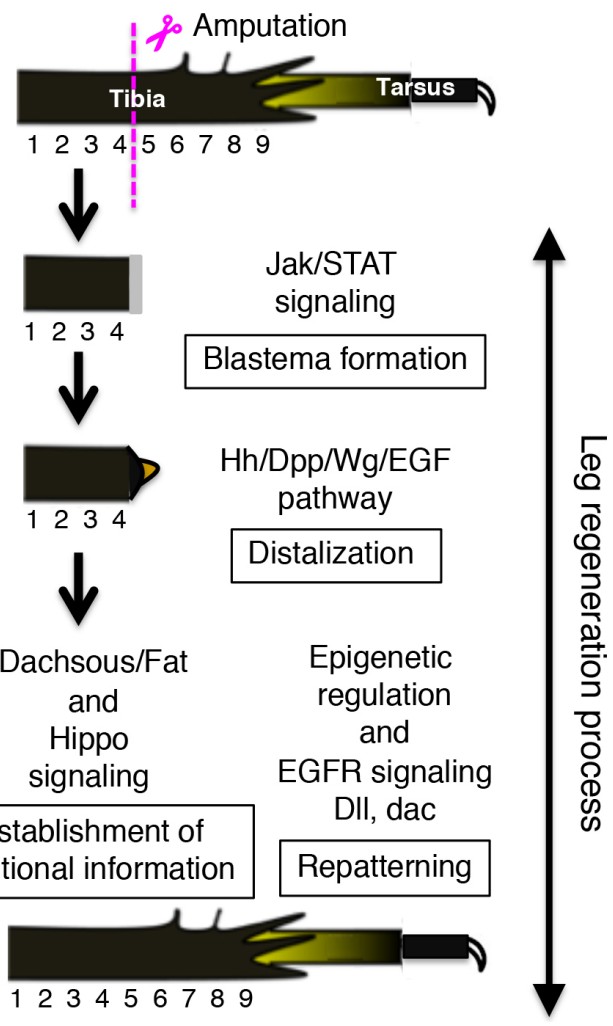

Fig. 10. Schematic diagrams of cricket leg regeneration process. Schematic diagram of the process of leg regeneration in cricket. After amputation, Jak/STAT signaling is required for blastema formation. Hh/Dpp/ Wg/EGF pathway instructs distalization in the blastema. Ds/Ft signaling establishes positional information of the regenerating tibia through Hippo signaling. Epigenetic regulation, EGFR signaling and transcription factors are involved in the leg repatterning process of regenerating tarsus. Positional value is denoted arbitrarily by numbers 1 9.
Fig. 9.The Ds/Ft steepness model. The extended steepness model: A Ds/Ft trans-heterodimer case. During cell division, the Ds/Ft heterodimers are deemed redistributed on the wall of the newly created cell. $\mathrm{I}_{\mathrm{d}}$ and $\mathrm{l}_{\mathrm{f}}$ are the initial number of Ds and Ft heterodimers in the left cell, while $r_{d}$ and $r_{f}$ are the initial number of Ds and Ft heterodimers in the right cell, respectively. The left and the right Ds/Ft molecules are redistributed during cell division under Formula 1, where $\mathrm{n}_{f}$ and $\mathrm{n}_{\mathrm{d}}$ are the number of Ft and Ds heterodimers in the new membrane of the divided cell. Cells can proliferate under Formula 2, where diff is a threshold value of the steepness for proliferation.
Lawrence et al., (Lawrence et al., 2008) described a steepness hypothesis linking PCP and cell growth, which are disconnected features of animal development, proposing that Ft and Ds link up to determine PCP and organ dimensions. Bando et al., (Bando et al., 2011b) proposed the Ds/Ft steepness model for intercalary regeneration and leg-size determination (Fig. $8 \mathrm{C}$ ), based on the Ds/Ft trans-dimer system (Fig. 9).

\section{Theoretical verification of the Ds/Ft steepness model}

The Ds/Ft steepness system may provide some positional information of the leg (Lawrence et al., 2008). To verify the steepness hypothesis, Yoshida and others proposed a mathematical model (Fig. 9) (Yoshida et al., 2014). They assumed that (1) Ds/ Ft trans-heterodimers or trans-homodimers are redistributed during cell division, and (2) growth would cease when a differential of the dimer across each cell decreases to a certain threshold (Yoshida et al., 2014). Their model was applied to simulate the results obtained by leg regeneration experiments with crickets. The simulated results were qualitatively consistent with the experimental data for leg regeneration of $G b^{\prime} d s^{\mathrm{RNAi}}$ or $G b^{\prime} f t^{\mathrm{RNAi}}$ nymphs, or intercalary regeneration. The similar results were obtained even if the gradient of transheterodimers was not linear. Thus, the Ds/Ft steepness model is the probable model for molecular mechanisms on leg regeneration.

\section{Concluding remarks}

The cricket is a potent model for studying how amputated legs can achieve full regeneration. Studies of cricket systems have led to an understanding of the molecular basis of the four major steps: (1) wound healing with clot/scab formation, (2) blastema formation, (3) establishment of positional information, and (4) repatterning of the leg (Fig. 10). This review has focused on candidate molecules and signaling pathways that are involved in leg regeneration. We have proposed a molecular basis of regeneration with the molecular boundary model for distalization and the Ds/Ft steepness model for intercalation, according to D\&I principle (Fig. 8C). Furthermore, we have demonstrated that epigenetics plays important roles in repatterning during regeneration.

With advances in whole-genome sequencing and gene-editing technologies, the tools needed to identify molecules and signaling cascades of leg regeneration processes are available. Genes expressed during regeneration can be manipulated to determine 
their functions, using a combination of RNA-seq data, rdRNAi, and genome editing methods with CRISPR/Cas (Supplemental information and Fig. S2). In addition to more precise investigation of molecular mechanisms in each step, how leg regeneration is initiated is one of the crucial and elusive questions to be answered for understanding the regenerative capacity in animals. This will be comprehensively understood soon, focusing on roles of macrophages in cricket.

\section{References}

AGATA, K., SAITO, Y. and NAKAJIMA, E. (2007). Unifying principles of regeneration I: Epimorphosis versus morphallaxis. Dev Growth Differ 49: 73-78.

ARBOUZOVA, N.I. and ZEIDLER, M.P. (2006). JAK/STAT signalling in Drosophila: insights into conserved regulatory and cellular functions. Development 133: 2605-2616.

BANDO, T., HAMADA, Y., KURITA, K., NAKAMURA, T., MITO, T., OHUCHI, H. and NOJI, S. (2011a). Lowfat, a mammalian Lix1 homologue, regulates leg size and growth under the Dachsous/Fat signaling pathway during tissue regeneration. Dev Dyn 240: 1440-1453.

BANDO, T., ISHIMARU, Y., KIDA, T., HAMADA, Y., MATSUOKA, Y., NAKAMURA, T., OHUCHI, H., NOJI, S. and MITO, T. (2013). Analysis of RNA-Seq data reveals involvement of JAK/STAT signalling during leg regeneration in the cricket Gryllus bimaculatus. Development 140: 959-964.

BANDO, T., MITO, T., MAEDA, Y., NAKAMURA, T., ITO, F., WATANABE, T., OHUCHI, H. and NOJI, S. (2009). Regulation of leg size and shape by the Dachsous/Fat signalling pathway during regeneration. Development 136: 2235-2245.

BANDO, T., MITO, T., NAKAMURA, T., OHUCHI, H. and NOJI, S. (2011b). Regulation of leg size and shape: involvement of the Dachsous-fat signaling pathway. Dev Dyn 240: 1028-1041.

BASLER, K. and STRUHL, G. (1994). Compartment boundaries and the control of Drosophila limb pattern by hedgehog protein. Nature 368: 208-214.

BOHN, H. (1971). [Intercalary regeneration and segmental gradients in the extremities of Leucophaea larvae (Blattaria): III. The origin of the intercalary regenerate]. Wilhelm Roux Arch Entwickl Mech Org 167: 209-221.

BRYANT, S.V., FRENCH, V. and BRYANT, P.J. (1981). Distal regeneration and symmetry. Science 212: 993-1002.

CAMPBELL, G. (2002). Distalization of the Drosophila leg by graded EGF-receptor activity. Nature 418: 781-785.

CAMPBELL, G. and TOMLINSON, A. (1995). Initiation of the proximodistal axis in insect legs. Development 121: 619-628.

CAMPBELL, G., WEAVER, T. and TOMLINSON, A. (1993). Axis specification in the developing Drosophila appendage: the role of wingless, decapentaplegic, and the homeobox gene aristaless. Cell 74: 1113-1123.

CHO, E., FENG, Y., RAUSKOLB, C., MAITRA, S., FEHON, R. and IRVINE, K.D. (2006). Delineation of a Fat tumor suppressor pathway. Nat Genet38: 1142-1150.

COHEN, S.M., BRONNER, G., KUTTNER, F., JURGENS, G. and JACKLE, H. (1989). Distal-less encodes a homoeodomain protein required for limb development in Drosophila. Nature 338: 432-434.

CRESSMAN, D.E., GREENBAUM, L.E., DEANGELIS, R.A., CILIBERTO, G., FURTH, E.E., POLI, V. and TAUB, R. (1996). Liver failure and defective hepatocyte regeneration in interleukin-6-deficient mice. Science 274: 1379-1383.

DAS, S. (2015). Morphological, Molecular, and Hormonal Basis of Limb Regeneration across Pancrustacea. Integr Comp Biol 55: 869-877.

DIAZ-BENJUMEA, F.J., COHEN, B. and COHEN, S.M. (1994). Cell interaction between compartments establishes the proximal-distal axis of Drosophila legs. Nature 372: 175-179.

DONG, P.D., CHU, J. and PANGANIBAN, G. (2001). Proximodistal domain specification and interactions in developing Drosophila appendages. Development 128: 2365-2372.

DONOUGHE, S. and EXTAVOUR, C.G. (2016). Embryonic development of the cricket Gryllus bimaculatus. Dev Biol 411: 140-156.

FRENCH, V. (1978). Intercalary regeneration around the circumference of the cockroach leg. J Embryol Exp Morphol 47: 53-84.
FRENCH, V., BRYANT, P.J. and BRYANT, S.V. (1976). Pattern regulation in epimorphic fields. Science 193: 969-981.

GALINDO, M.I., BISHOP, S.A., GREIG, S. and COUSO, J.P. (2002). Leg patterning driven by proximal-distal interactions and EGFR signaling. Science 297: 256-259.

GALLIOT, B. (2013). Injury-induced asymmetric cell death as a driving force for head regeneration in Hydra. Dev Genes Evol 223: 39-52.

GOTO, S. and HAYASHI, S. (1999). Proximal to distal cell communication in the Drosophila leg provides a basis for an intercalary mechanism of limb patterning. Development 126: 3407-3413.

HAAS, B.J. and WHITED, J.L. (2017). Advances in Decoding Axolotl Limb Regeneration. Trends Genet 33: 553-565.

HAMADA, Y., BANDO, T., NAKAMURA, T., ISHIMARU, Y., MITO, T., NOJI, S., TOMIOKA, K. and OHUCHI, H. (2015). Leg regeneration is epigenetically regulated by histone H3K27 methylation in the cricket Gryllus bimaculatus. Development 142: 2916-2927.

HARVEY, K.F. and HARIHARAN, I.K. (2012). The hippo pathway. Cold Spring Harb Perspect Biol 4: a011288.

HARVEY, K.F., ZHANG, X. and THOMAS, D.M. (2013). The Hippo pathway and human cancer. Nat Rev Cancer 13: 246-257.

HAYASHI, S., KAWAGUCHI, A., UCHIYAMA, I., KAWASUMI-KITA, A., KOBAYASHI, T. NISHIDE, H., TSUTSUMI, R., TSURU, K., INOUE, T., OGINO, H. et al., (2015a). Epigenetic modification maintains intrinsic limb-cell identity in Xenopus limb bud regeneration. Dev Biol 406: 271-282.

HAYASHI, S., YOKOYAMA, H. and TAMURA, K. (2015b). Roles of Hippo signaling pathway in size control of organ regeneration. Dev Growth Differ 57: 341-351.

INOUE, Y., MITO, T., MIYAWAKI, K., MATSUSHIMA, K., SHINMYO, Y., HEANUE, T.A., MARDON, G., OHUCHI, H. and NOJI, S. (2002). Correlation of expression patterns of homothorax, dachshund, and Distal-less with the proximodistal segmentation of the cricket leg bud. Mech Dev 113: 141-148.

ISHIMARU, Y., NAKAMURA, T., BANDO, T., MATSUOKA, Y., OHUCHI, H., NOJI, S and MITO, T. (2015). Involvement of dachshund and Distal-less in distal pattern formation of the cricket leg during regeneration. Sci Rep 5: 8387.

KATSUYAMA, T. and PARO, R. (2011). Epigenetic reprogramming during tissue regeneration. FEBS Lett 585: 1617-1624.

KOJIMA, T. (2004). The mechanism of Drosophila leg development along the proximodistal axis. Dev Growth Differ 46: 115-129.

LAWRENCE, P.A., STRUHL, G. and CASAL, J. (2008). Do the protocadherins Fat and Dachsous link up to determine both planar cell polarity and the dimensions of organs? Nat Cell Biol 10: 1379-1382.

LI, W., LIANG, X., KELLENDONK, C., POLI, V. and TAUB, R. (2002). STAT3 contributes to the mitogenic response of hepatocytes during liver regeneration. $J$ Biol Chem 277: 28411-28417.

MARDON, G., SOLOMON, N.M. and RUBIN, G.M. (1994). dachshund encodes a nuclear protein required for normal eye and leg development in Drosophila. Development 120: 3473-3486.

MATSUOKA, Y., BANDO, T., WATANABE, T., ISHIMARU, Y., NOJI, S., POPADIC, A. and MITO, T. (2015). Short germ insects utilize both the ancestral and derived mode of Polycomb group-mediated epigenetic silencing of Hox genes. Biol Open 4: 702-709.

MEINHARDT, H. (1982). Models of biological pattern formation. Academic Press, London; New York.

MEINHARDT, H. (1983). Cell determination boundaries as organizing regions for secondary embryonic fields. Dev Biol 96: 375-385.

MESCHER, A.L. (2017). Macrophages and fibroblasts during inflammation and tissue repair in models of organ regeneration. Regeneration (Oxf) 4: 39-53.

MITO, T., INOUE, Y., KIMURA, S., MIYAWAKI, K., NIWA, N., SHINMYO, Y., OHU$\mathrm{CHI}, \mathrm{H}$. and NOJI, S. (2002). Involvement of hedgehog, wingless, and dpp in the initiation of proximodistal axis formation during the regeneration of insect legs, a verification of the modified boundary model. Mech Dev 114: 27-35.

MITO, T. and NOJI, S. (2008). The Two-Spotted Cricket Gryllus bimaculatus: An Emerging Model for Developmental and Regeneration Studies. CSH Protoc 2008: pdb emo110.

MORGAN, T.H. (1901). Regeneration and Liability to Injury. Science 14: 235-248.

NACU, E., GROMBERG, E., OLIVEIRA, C.R., DRECHSEL, D. and TANAKA, E.M. (2016). FGF8 and SHH substitute for anterior-posterior tissue interactions to 
induce limb regeneration. Nature 533: 407-410.

NACU, E. and TANAKA, E.M. (2011). Limb regeneration: a new development? Annu Rev Cell Dev Biol 27: 409-440.

NAKAMURA, T., MITO, T., BANDO, T., OHUCHI, H. and NOJI, S. (2008a). Dissecting insect leg regeneration through RNA interference. Cell Mol Life Sci 65: 64-72.

NAKAMURA, T., MITO, T., MIYAWAKI, K., OHUCHI, H. and NOJI, S. (2008b). EGFR signaling is required for re-establishing the proximodistal axis during distal leg regeneration in the cricket Gryllus bimaculatus nymph. Dev Biol 319: 46-55.

NIWA, N., INOUE, Y., NOZAWA, A., SAITO, M., MISUMI, Y., OHUCHI, H., YOSHIOKA, H. and NOJI, S. (2000). Correlation of diversity of leg morphology in Gryllus bimaculatus (cricket) with divergence in dpp expression pattern during leg development. Development 127: 4373-4381.

PETERSEN, C.P. and REDDIEN, P.W. (2009). A wound-induced Wnt expression program controls planarian regeneration polarity. Proc Natl Acad Sci USA 106: 17061-17066.

REPISO, A., BERGANTINOS, C., COROMINAS, M. and SERRAS, F. (2011). Tissue repair and regeneration in Drosophilaimaginal discs. Dev Growth Differ53: 177-185.

RIECKHOF, G.E., CASARES, F., RYOO, H.D., ABU-SHAAR, M. and MANN, R.S. (1997). Nuclear translocation of extradenticle requires homothorax, which encodes an extradenticle-related homeodomain protein. Cell 91: 171-183.

SATOH, A., MAKANAE, A., HIRATA, A. and SATOU, Y. (2011). Blastema induction in aneurogenic state and Prrx-1 regulation by MMPs and FGFs in Ambystoma mexicanum limb regeneration. Dev Biol 355: 263-274.

STALEY, B.K. and IRVINE, K.D. (2010). Warts and Yorkie mediate intestinal regeneration by influencing stem cell proliferation. Curr Biol 20: 1580-1587.

STALEY, B.K. and IRVINE, K.D. (2012). Hippo signaling in Drosophila: recent advances and insights. Dev Dyn 241: 3-15.

SUGIURA, T., WANG, H., BARSACCHI, R., SIMON, A. and TANAKA, E.M. (2016). MARCKS-like protein is an initiating molecule in axolotl appendage regeneration. Nature 531: 237-40.

SUZUKI, M., TAKAGI, C., MIURA, S., SAKANE, Y., SUZUKI, M., SAKUMA, T., SAKAMOTO, N., ENDO, T., KAMEI, Y., SATO, Y. et al., (2016). In vivo tracking of histone $\mathrm{H} 3$ lysine 9 acetylation in Xenopus laevis during tail regeneration. Genes Cells 21: 358-369.

TANAKA, E.M. (2016). The Molecular and Cellular Choreography of Appendage Regeneration. Cell 165: 1598-1608.

TASAKI, J., SHIBATA, N., NISHIMURA, O., ITOMI, K., TABATA, Y., SON, F., SUZUKI, N., ARAKI, R., ABE, M., AGATA, K. et al., (2011a). ERK signaling controls blastema cell differentiation during planarian regeneration. Development 138: 2417-2427.
TASAKI, J., SHIBATA, N., SAKURAI, T., AGATA, K. and UMESONO, Y. (2011b). Role of c-Jun N-terminal kinase activation in blastema formation during planarian regeneration. Dev Growth Differ 53: 389-400

TIE, F., BANERJEE, R., STRATTON, C.A., PRASAD-SINHA, J., STEPANIK, V., ZLOBIN, A., DIAZ, M.O., SCACHERI, P.C. and HARTE, P.J. (2009). CBP-mediated acetylation of histone $\mathrm{H} 3$ lysine 27 antagonizes Drosophila Polycomb silencing. Development 136: 3131-3141.

TRUBY, P.R. (1983). Blastema formation and cell division during cockroach limb regeneration. J Embryol Exp Morphol 75: 151-164.

UMESONO, Y., TASAKI, J., NISHIMURA, Y., HROUDA, M., KAWAGUCHI, E., YAZAWA, S., NISHIMURA, O., HOSODA, K., INOUE, T. and AGATA, K. (2013). The molecular logic for planarian regeneration along the anterior-posterior axis. Nature 500: 73-76.

VINCENT, J.P. and LAWRENCE, P.A. (1994). Developmental genetics. It takes three to distalize. Nature $372: 132-133$.

WILSON-HORCH, H., MITO, T., OHUCHI, H. and NOJI, S. (2017). The Cricket as a Model Organism. Springer Japan, Japan.

WU, J. and COHEN, S.M. (1999). Proximodistal axis formation in the Drosophila leg: subdivision into proximal and distal domains by Homothorax and Distal-less. Development 126: 109-117.

WUESTEFELD, T., KLEIN, C., STREETZ, K.L., BETZ, U., LAUBER, J., BUER, J., MANNS, M.P., MULLER, W. and TRAUTWEIN, C. (2003). Interleukin-6/glycoprotein 130-dependent pathways are protective during liver regeneration. J Biol Chem 278: 11281-11288.

YAKUSHIJI, N., SUZUKI, M., SATOH, A., SAGAI, T., SHIROISHI, T., KOBAYASHI, H., SASAKI, H., IDE, H. and TAMURA, K. (2007). Correlation between Shh expression and DNA methylation status of the limb-specific Shh enhancer region during limb regeneration in amphibians. Dev Biol 312: 171-182.

YAKUSHIJI-KAMINATSUI, N., KONDO, T., ENDO, T.A., KOSEKI, Y., KONDO, K. OHARA, O., VIDAL, M. and KOSEKI, H. (2016). RING1 proteins contribute to early proximal-distal specification of the forelimb bud by restricting Meis2 expression. Development 143: 276-285.

YAZAWA, S., UMESONO, Y., HAYASHI, T., TARUI, H. and AGATA, K. (2009). Planarian Hedgehog/Patched establishes anterior-posterior polarity by regulating Wnt signaling. Proc Natl Acad Sci USA 106: 22329-22334.

YOSHIDA, H., BANDO, T., MITO, T., OHUCHI, H. and NOJI, S. (2014). An extended steepness model for leg-size determination based on Dachsous/Fat trans-dimer system. Sci Rep 4: 4335.

YUN, M.H. (2015). Changes in Regenerative Capacity through Lifespan. Int J Mol Sci 16: 25392-25432. 


\section{Further Related Reading, published previously in the Int. J. Dev. Biol.}

Leg regeneration in Drosophila abridges the normal developmental program

Manel Bosch, Sarah-Anne Bishop, Jaume Baguña and Juan-Pablo Couso

Int. J. Dev. Biol. (2010) 54: 1241-1250

https://doi.org/10.1387/ijdb.093010mb

Regeneration and pattern formation - an interview with Susan Bryant

Michael K. Richardson and Cheng Ming Chuong

Int. J. Dev. Biol. (2009) 53: 827-833

https://doi.org/10.1387/ijdb.082596mr

\section{Limb muscle development}

Bodo Christ and Beate Brand-Saberi

Int. J. Dev. Biol. (2002) 46: 905-914

http://www.intjdevbiol.com/web/paper/12455628

The cellular basis of limb regeneration in urodeles

A L Mescher

Int. J. Dev. Biol. (1996) 40: 785-795

http://www.intjdevbiol.com/web/paper/8877452

Cell interactions and regeneration control

B Boilly, E Lheureux, Y Boilly-Marer and A Bart

Int. J. Dev. Biol. (1990) 34: 219-231

http://www.intjdevbiol.com/web/paper/2203459

Localization of regenectin in regenerates of American cockroach (Periplaneta americana) legs

T Kubo, K Kawasaki, Y Nonomura and S Natori

Int. J. Dev. Biol. (1991) 35: 83-90

http://www.intjdevbiol.com/web/paper/1768603

Purification and localization of p10, a novel protein that increases in nymphal regenerating legs of Periplaneta americana (American cockroach)

A Nomura, K Kawasaki, T Kubo and S Natori

Int. J. Dev. Biol. (1992) 36: 391-398

http://www.intjdevbiol.com/web/paper/1445782

5 yr ISI Impact Factor $(2016)=2.421$

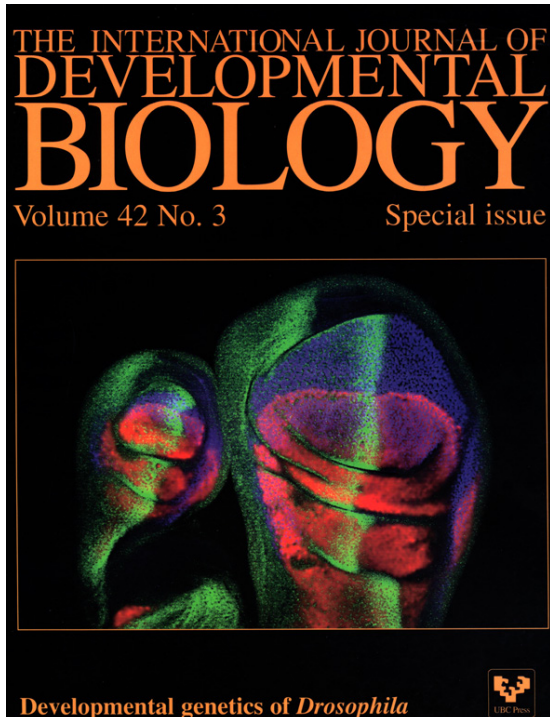

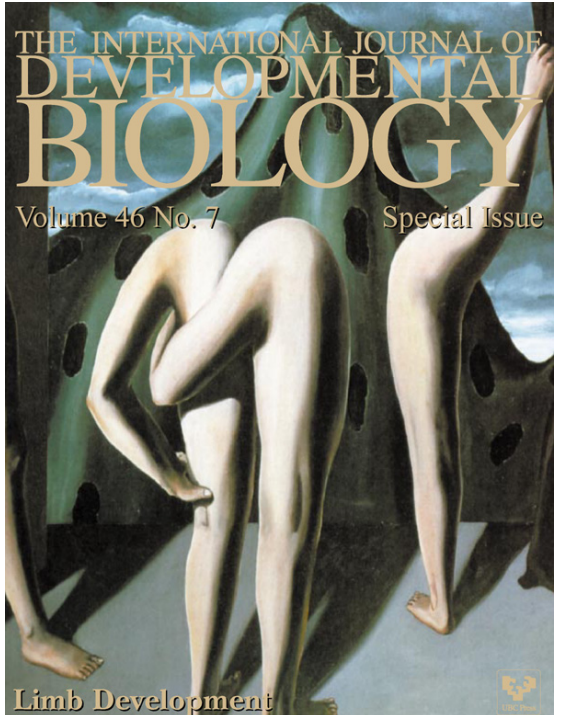
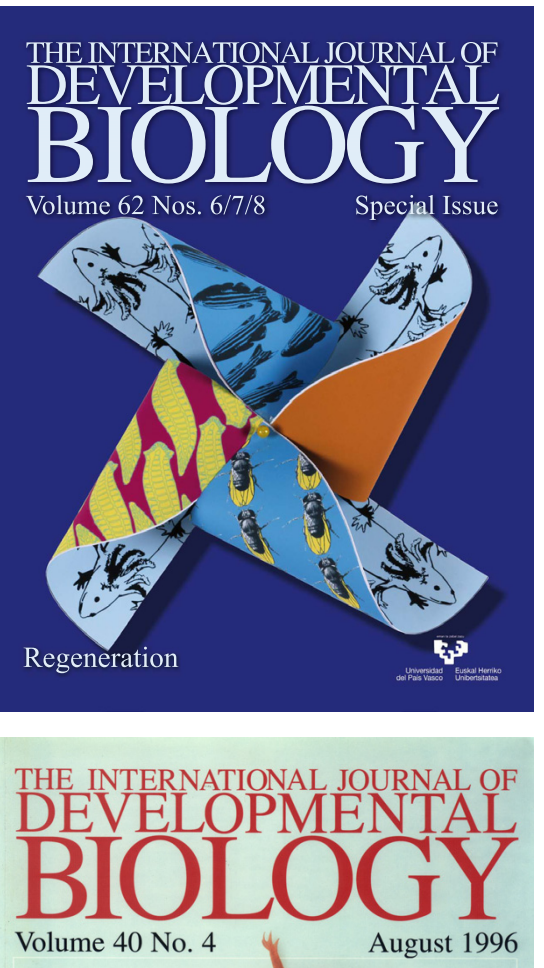

Volume 40 No. 4 August 1996

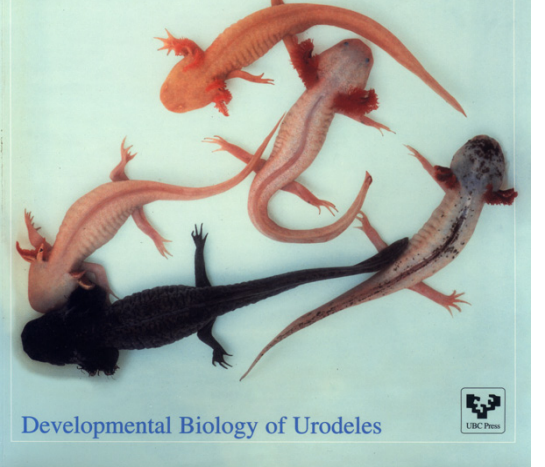

